\title{
Development of a Charge Controller Dedicated to the Small Wind Turbine System
}

\author{
Ababacar Ndiaye $^{1,2}$, Cheikh M. F. Kébé ${ }^{2}$, Vincent Sambou ${ }^{2} \&$ Papa A. Ndiaye ${ }^{2}$ \\ ${ }^{1}$ Université Assane Seck de Ziguinchor, UFR Sciences et Technologies, Département de Physique. BP: 523 \\ Ziguinchor, Sénégal \\ ${ }^{2}$ Centre International de Formation et de Recherche en Energie Solaire (CIFRES), Ecole Supérieure \\ Polytechnique-Université Cheikh Anta Diop de Dakar (UCAD), BP 5085 Dakar-Fann, Sénégal \\ Correspondence: Ababacar Ndiaye, Université Assane Seck de Ziguinchor, UFR Sciences et Technologies, \\ Département de Physique. BP: 523 Ziguinchor, Sénégal. Tel: 221-77-654-6393. E-mail: ab.ndiaye@univ-zig.sn
}

Received: April 10, 2013 Accepted: May 26, 2013 Online Published: October 24, 2014

doi:10.5539/eer.v4n3p68 URL: http://dx.doi.org/10.5539/eer.v4n3p68

\begin{abstract}
In this paper, we present the development of charge and discharge controller of battery used in low power wind applications. This controller allows on the one hand protecting the battery against overcharging and deep discharge. On the other hand, it helps to protect the turbine against strong winds. It is controlled by PIC microcontroller $16 \mathrm{~F} 877 \mathrm{~A}$. This control function is performed using an algorithm that continuously compares the battery voltage to the charge and discharge thresholds, and tilting towards dissipation resistors. The control signals generated by the microcontroller are PWM (Pulse Width Modulation) type. The validation of the main functions of the controller is presented.
\end{abstract}

Keywords: wind power generator, microcontroller, PIC16F877A, pulse width modulation, MOSFET, battery

\section{Introduction}

As in photovoltaic systems, wind energy applications include most often batteries for storing excess energy and feed loads low and medium powers. The batteries are weak with the phenomena of overloading and deep discharge. This adversely affects the life of the batteries and is a weak point for renewable energies. To protect the batteries and prolong their lives, a controller should be used. For photovoltaic systems, the controller can only protect the batteries. The principle often used for photovoltaic controller consists in disconnecting the PV generator from the batteries. This disconnection occurs when the batteries are fully charged or deeply discharged (Amin et al., 2008). For wind turbine applications, the same principle cannot be used. Indeed, we cannot afford to disconnect the turbine from the batteries and keep it in a vacuum which will increase the risk of its destruction by overspeed. The principle adopted for the control of the batteries charge/ discharge for wind systems must take into account this constraint. The wind turbine must always be loaded by the batteries and/or other charges (use, discharge resistors). In addition to the batteries, the controller protects the wind turbine.

The importance of a charging / discharging controller in an autonomous system such as a photovoltaic system or wind turbine needs no more to be discussed. However, it must be done very carefully in order to meet the requirements for reliability, simplicity, portability and cost. As in the embodiment of any system, the controller also poses a number of problems related to the existence of several possible architectures for load control (Usher \& Ross, 1998; Koutroulis \& Kalaitzakis, 2004) (maximum charging current with control battery voltage, constant voltage charging with control current battery, charging with adjustable intensity together with control of the battery voltage, etc..) and battery discharge (Usher \& Ross, 1998) (direct control of the battery voltage, check the battery voltage compensated or not the discharge current, discharge control across the state of battery charge. Several solutions are possible: analog, digital or mixed.

Additional constraints imposed on the controller such as the possibility of varying the parameters of the control algorithm and display the battery charge level, increase its complexity and lead us to opt for a smart solution based on microcontrollers.

This paper presents the different development steps of a battery controller for wind turbine applications, operating under the control of the microcontroller PIC16F877A. 


\section{Wind Turbine System}

\subsection{Operational Mode}

The wind turbine is a device that converts kinetic energy from the wind into mechanical energy. The moving air passes through the section of the active surface of the airfoil. The power of the mass of air passing through this active surface is partially recovered by the turbine in the form of mechanical energy. According to BETZ law, only $59 \%$ of this power is recoverable.

It is necessary to know as accurately as possible the behavior of the wind depending on various parameters. Figure 1 below shows the power curve of a wind turbine in function of wind speed. In part (A) no power is delivered by the turbine for wind speeds lower than the starting speed $\mathrm{V}_{\text {min. }}$. If the maximum power is extracted from the wind turbine for each wind speed, cubic variation of wind speed is obtained in part (B). Beyond a certain limit of wind speed, the rated power of the turbine is reached. Then the latter must be stopped.

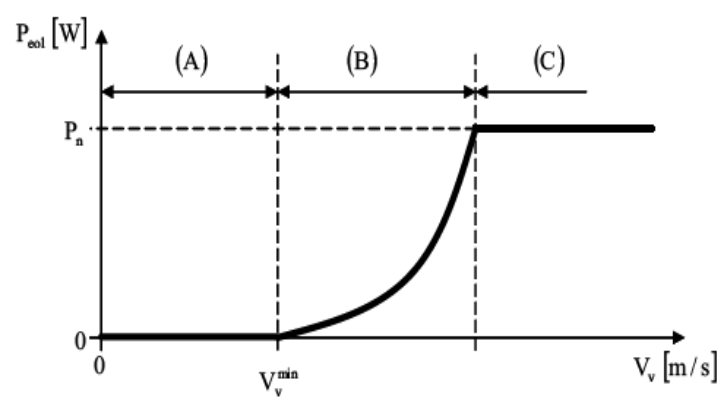

Figure 1. Power curve of a wind turbine depending on the wind speed

\subsection{The Wind Turbine Control}

There are occasional periods of gusty wind that inflict serious mechanical constraints to rotating parts. To prevent their destruction when the winds are of high intensity, the wind turbine must be equipped with a control board. This card is also used to operate the electrical energy delivered by the wind turbine to charge batteries. The voltage supplied by the wind turbine is a three phase system. It attacks a diode bridge to provide DC voltage. This DC voltage is used by the board to charge the batteries. When the batteries are sufficiently charged the excess of production must be consumed in order to prevent the destruction of the wind turbine. Figure 2 shows the chain formed by wind, controller, battery and load.

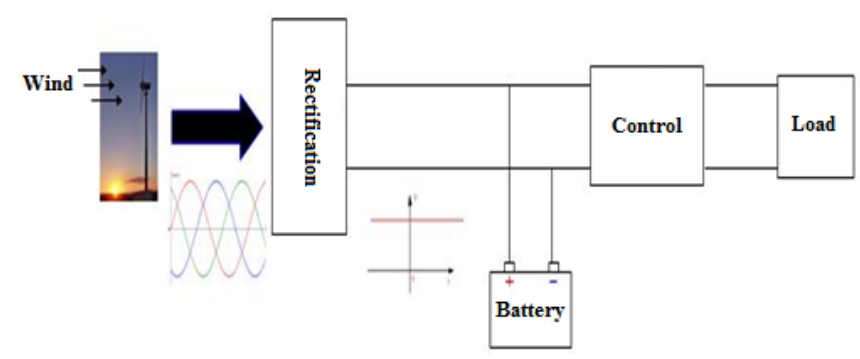

Figure 2. Wind turbine/ Controller/ Battery/ Load

\section{Control Principle}

The primary function of this controller is to allow the battery charging while ensuring that it is not overloaded. In fact, the battery has a high load threshold given by the manufacturer. If the battery voltage exceeds the threshold for an extended period, it can cause destruction of the batteries. To perform this control function of the load, there is a dedicated block. The principle on which the charge control block works is as follows: the voltage seen by the battery will continuously be measured. If it exceeds the high threshold, a resistor is connected in parallel with the battery to dissipate the energy excess provided by the wind turbine. This resistor must be variable in order to be adaptable to the power to be dissipated which also varies with the turbine production. The second function of the controller is to allow the discharge of the battery, while ensuring that it is not deeply discharged. 
In fact, the battery has a low threshold for discharge given by the manufacturer. If the battery voltage exceeds the threshold for an extended period, it can cause the destruction of the batteries.

The control block of the discharge operates on the following principle: the voltage seen by the battery will continuously be measured. If it is inferior to the low threshold of the battery then the load is disconnected. The controller includes a third function, whose role is to inform the user on the charge level of the battery in real time. This information will be through three LEDs: green, yellow and red. Indeed, in addition to the high and low thresholds given by the manufacturer, we define a transition range between the low threshold and the high threshold.

This function is carried out according to the principle described below. The voltage seen by the battery is continuously measured. If it is below the lower threshold then the red LED is lit. This state corresponds to a level of deep discharge and therefore loads are shed. If it is greater than the upper threshold then the green LED lights. This condition corresponds to a correct level of charge and therefore the loads can be connected. If one is in the range between the two upper and lower thresholds then the yellow LED is lit. This state corresponds to the first alert.

\section{Development of the Hardware Controller}

The proposed controller is divided into three blocks: the control unit, the power unit (charge and discharge) and the block level meter (charge). Figure 3 shows the block diagram of the developed controller.

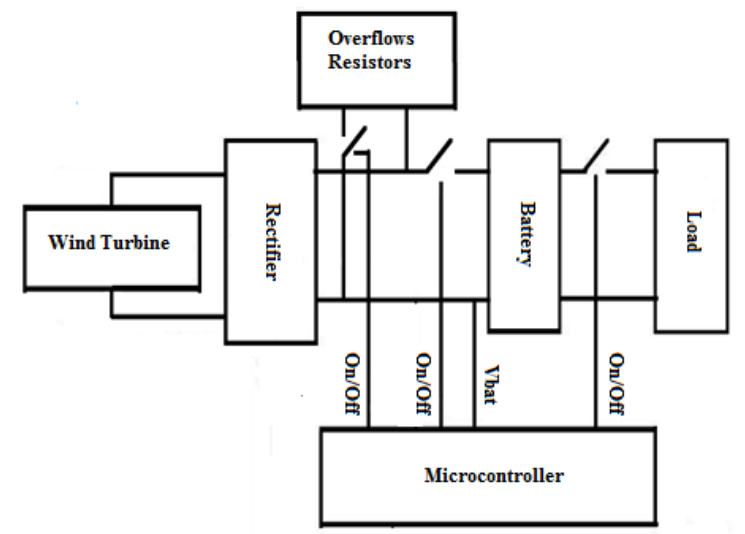

Figure 3. Block diagram of the whole Wind turbine / Controller / Load

\subsection{The Control Block}

Figure 4 shows the diagram of the control unit which consists essentially of the microcontroller PIC16F877A, its $20 \mathrm{MHz}$ clock circuit and its initialization circuit. It also includes a $5 \mathrm{~V}$ power supply circuit for the microcontroller and voltage divider resistors with a variable potentiometer setting. The PIC 16F877A (Datasheet PIC 16F877A, 2012) is the key control block. It allows running the program corresponding to the operation of the controller. This is a Microchip microcontroller. The clock circuit is realized around a $20 \mathrm{MHz}$ frequency quartz imposing the operating frequency of the PIC. The "Return To Zero" resets the microcontroller to reconfigure the controller. The battery voltage Vbat is measured through the RA0 pin of PIC configured as Analog/Digital input. The PIC only admits as analog input, voltages ranging from 0 to 5 volts. It is therefore necessary to adjust the battery voltage Vbat in the $0 / 5$ volts range. A voltage divider resistor consisting of RV1, R14 and R15 was used. RV1 is a variable resistor for the calibration of the bridge and better accuracy. For a $24 \mathrm{~V}$ (1), the divider is made up of R14 and RV1. The selection between R14 and R15 is via a jumper.

$$
\begin{aligned}
& \mathrm{Va}=\frac{\mathrm{RV} 1}{\mathrm{R} 14+\mathrm{RV} 1} V_{\text {bat }} \\
& \mathrm{Va}=\frac{\mathrm{RV} 1}{\mathrm{R} 15+\mathrm{RV} 1} V_{\text {bat }}
\end{aligned}
$$

The value measured through the voltage divider is then converted into a digital value $\mathrm{Vn}$ through an integrated internal analog to digital converter (ADC) (Ndiaye et al., 2012). 


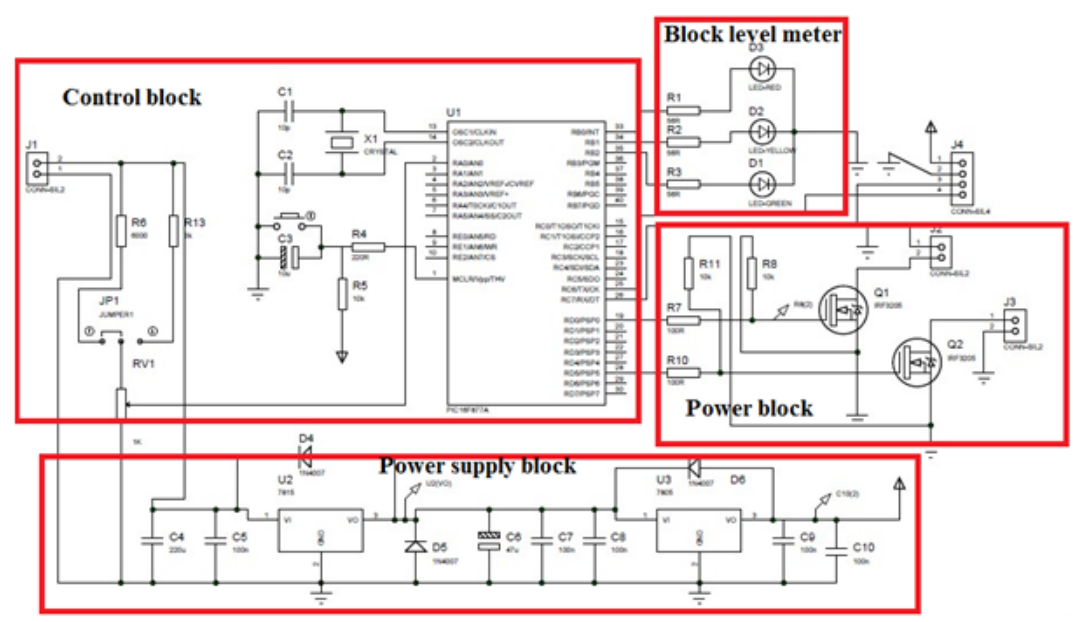

Figure 4. Electrical Schematic of the controller

\subsection{The Power System}

The power system consists of three blocks (Figure 4): the power supply unit (power supply block), the Power block (control charging/discharging) and the display unit of the battery charge level (block level meter).The power supply unit generates, from the battery voltage, a DC voltage of $5 \mathrm{~V}$ for powering the microcontroller (Figure 4). It integrates two 7805 regulators (Ndiaye et al., 2010). The control blocks of the battery charging and discharging use PWM commands signals for controlling the charging and discharging of the battery. PWM signals generated by the PIC control the opening/ closing IRF3205 MOSFET transistors (Ndiaye et al., 2012).

For the control, an IRF3205 MOSFET transistor is used and connected to the overflow resistor. The resistor has been dimensioned in relation to the maximum power corresponding to excess energy production to be dissipated in order to avoid battery overcharging. According to the over-production, the overflow resistor will dissipate power variably. For discharge control, the block is composed of an IRF3205 MOSFET transistor connected to a pulling resistor $(56 \Omega)$. It is controlled by the PWM signal generated by the microcontroller. The connection of the load (use) is done by through the transistor. Thus, when the low threshold of the battery is reached, the duty cycle is very low and the load is no longer supplied. When the upper threshold of the battery is reached, the load is supplied again.

One block measures the battery voltage continuously. A voltage divider converts this voltage into the voltage range allowable by PIC microcontroller between $0 \mathrm{~V}$ and $5 \mathrm{~V}$. Depending on the value of this signal, the microcontroller generates the digital signal for each transistor according to its function. A display unit of the battery charge level is integrated into the board. It consists of three LEDs of different colors. Depending on the signal generated by the PIC, the LEDs light up to indicate the battery status: Green (fully charged battery), Yellow (moderately charged battery) and Red (flat battery).

\section{Development of the Software Part of the Controller}

\subsection{Presentation of the Operation Flow Chart}

The algorithm to implement is symbolized by the main flowchart in Figure 5. This flowchart describes the general principle of the controller operation. The program is based on a comparing test of the battery voltage to the various thresholds continuously during the controller operation. The program is described in a flowchart to facilitate understanding. It has three sub-charts; each one explains the progress of each phase of the algorithm charging to be implemented:

- Flowchart of the charging phase « Float»,

- Flowchart of the charging phase « Absorption»,

- Flowchart of the discharging phase «Bulk».

Depending on the state of battery charge $\left(\mathrm{V}_{\text {batt }}\right)$, the program switches to the charge phase suitable. 


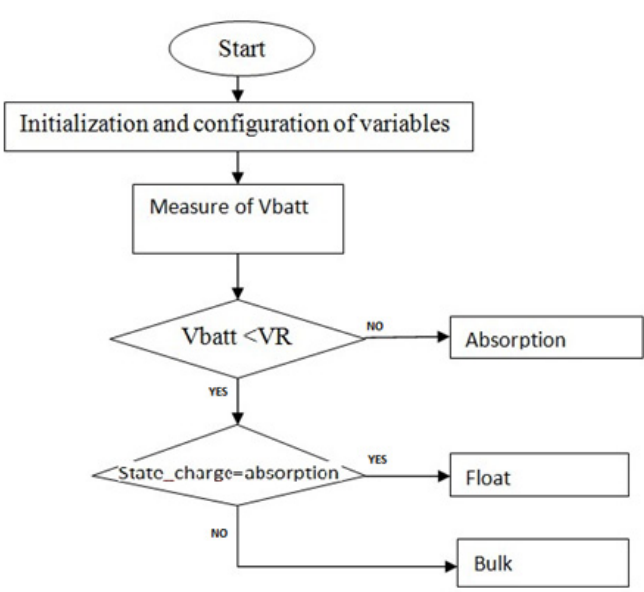

Figure 5. The main flowchart of controller

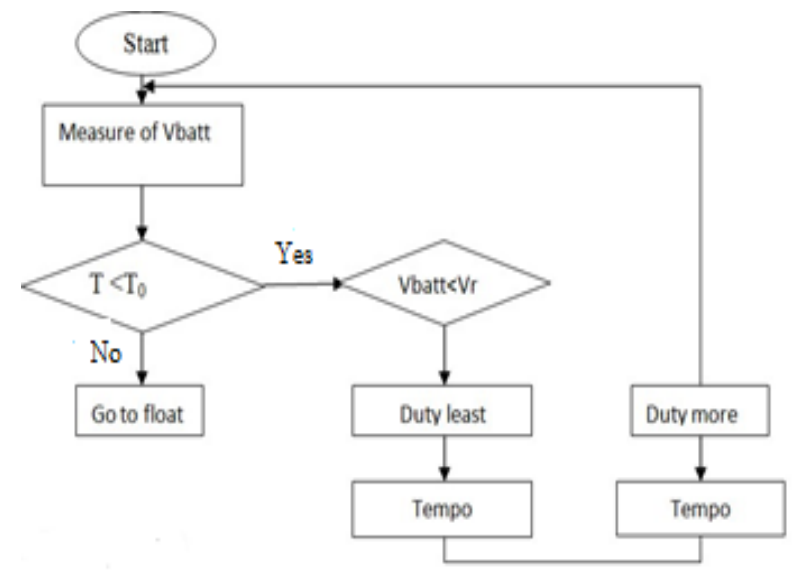

Figure 6. Flowchart of phase "Absorption"

"Absorption" Phase achieves a full charge of the battery that was previously less than $80 \%$. During this phase, the voltage is kept constant (VR) allowing more or less dissipation (Duty more, Duty least). This step is only completed after a time $\mathrm{T}=\mathrm{T}_{0}$. During our tests, $\mathrm{T}_{0}$ is set to 1hour (Huet, 1998). The corresponding flowchart is given in Figure 6.

"Float" Phase maintains the constant voltage to $\mathrm{V}_{\text {float }}$ value slightly lower VR. This voltage prevents self-discharge (holding voltage). Depending on the state of charge $\left(\mathrm{V}_{\text {batt }}\right)$, more or less dissipation is permitted (Duty more, Duty least) with a delay (tempo). In the case of our test $\mathrm{V}_{\text {float }}=26.8$ volts and tempo $=1$ second (Huet, 1998). Its flowchart is given in Figure 7.

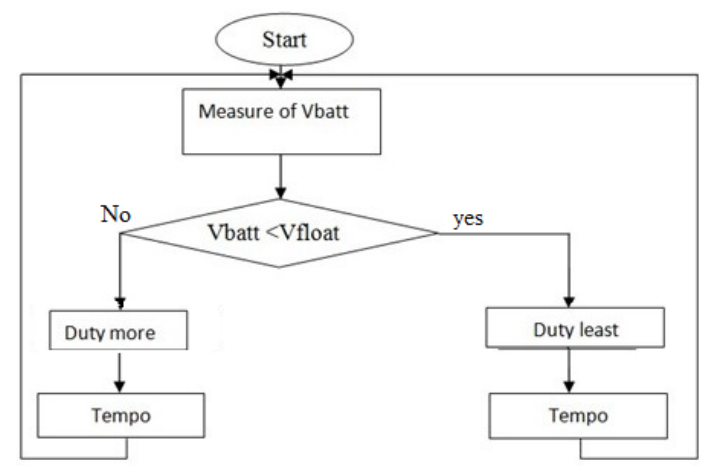

Figure 7. Flowchart of phase "Float"

It is in the "Bulk" phase whose the flowchart is given in Figure 8 that the permission or the prohibition to connect a load is taken. A voltage lower than $V_{l v d}$, indicates that the use of the battery is not allowed. When the battery voltage $V_{\text {batt }}$ reaches the reconnection voltage $V A R$, the use becomes authorized.

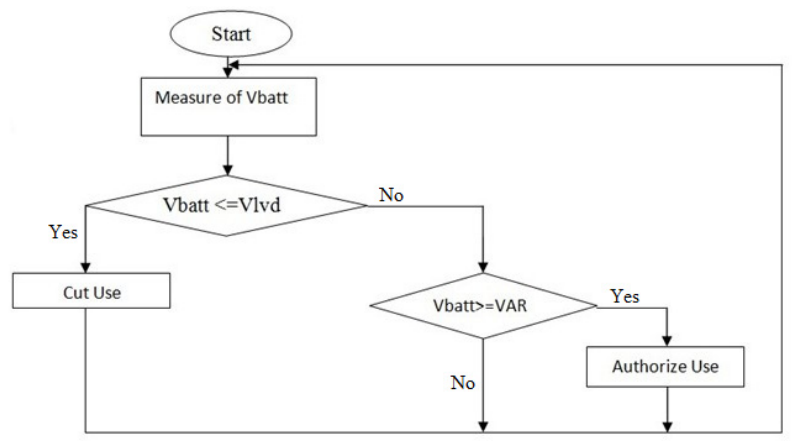

Figure 8. Flowchart of phase "Bulk" 


\subsection{The Programmer}

A programmer is necessary to implement the program in the microcontroller. Several architectures are available on the literature. However, some of these make it possible to program only one PIC category, it is important to choose a programmer that recognize the PIC16F877A (Mayeux, 2002; Kirchev, 2007). The program developed in $\mathrm{C}$ and compiled on a computer must be sent to the PIC. But in the output of the computer we have a RS232 connector that sends information on $+12 \mathrm{~V} /-12 \mathrm{~V}$. However, the PIC only supports voltages between $0 \mathrm{~V}$ and $5 \mathrm{~V}$, so we must develop a device for performing this conversion function $\pm 12 \mathrm{~V}$ to $0 / 5 \mathrm{~V}$. This device shown in Figure. 9 is formed around an integrated circuit named MAX 232.

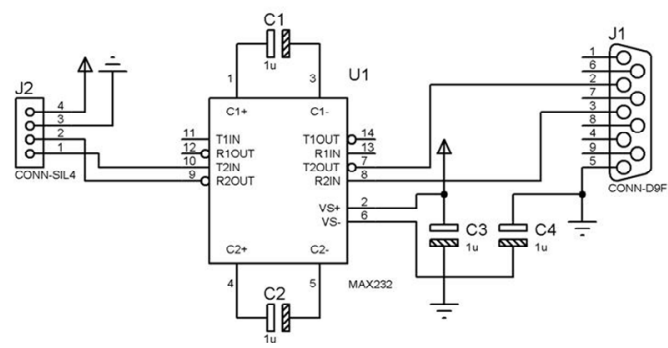

Figure 9. Electrical diagram of PIC programmer

It integrates a serial port (J1) to the computer, and allows transferring quickly and easily compiled program by SourceBoost tool to the microcontroller flash memory via Tinybootloader environment. The programming board thus produced is shown in Figure 10. The MAX 232 component around which is performed can clearly be identified, as well as links connecting the programmer to the computer on one side and to the controller board on the other hand.

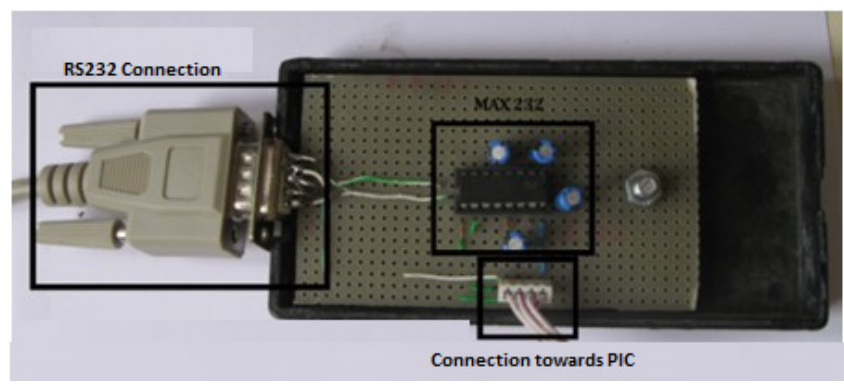

Figure 10. The programmer card

\section{Tests and Experimental Results}

\subsection{Presentation of the Test Platform}

Figure 11 shows the test platform. It consists of a power supply, a PC, an oscilloscope and the controller. The PC contains the elements of our development tool: software editing SourceBoost, and IC-PROG software for download the program to the microcontroller. Stabilized power supply is used to simulate the voltage after rectification of the wind turbine output voltage. The oscilloscope is used to visualize the individual signals such as the duty cycles and the different voltages of the controller board.

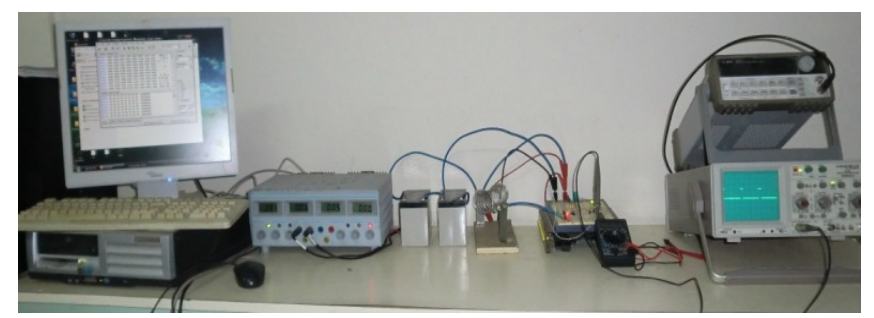

Figure 11. The test platform 


\subsection{Presentation of the Experimental Device}

The realization of wind turbine controller took place at the International Center for Training and Research in Solar Energy (ICTRSE) of Dakar University. As mentioned earlier, this controller consists of a power unit, a display unit of battery charge level and a control block around the PIC microcontroller. Figure 12 shows the controller on the platform test.

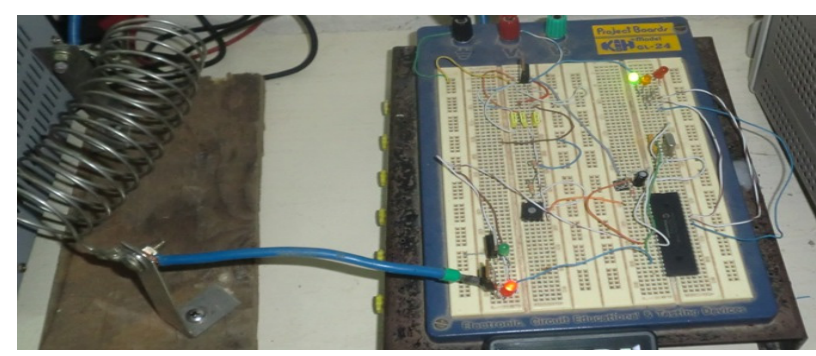

Figure 12. Presentation of the device on the test platform

\subsection{Presentation of Tests Results}

\subsubsection{Test of the Voltage Divider}

Before the voltage divider block is permanently connected to the microcontroller, it is tested to ensure proper operating condition. Measurements of the output voltage of the voltage divider $\left(\mathrm{V}_{\mathrm{a}}\right)$ were obtained for different battery voltage $\mathrm{V}_{\text {batt. }}$.

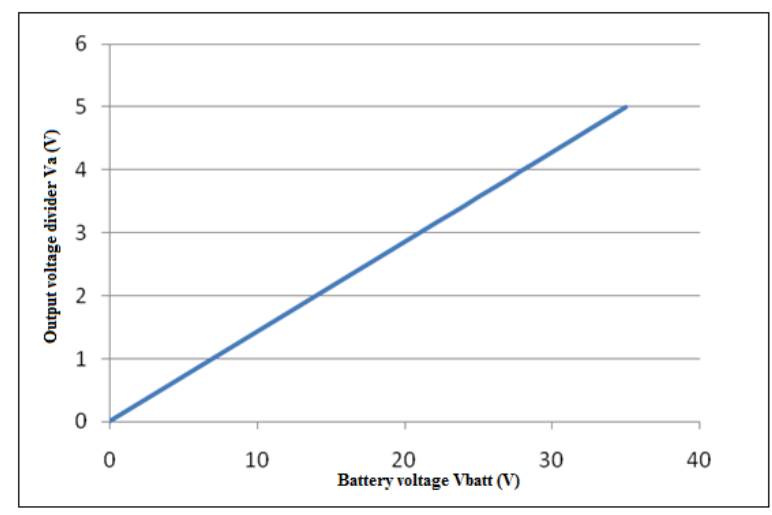

Figure 13. Output voltage divider block $\left(\mathrm{V}_{\mathrm{a}}\right)$ in function of the battery voltage $\left(\mathrm{V}_{\text {batt }}\right)$

The output voltage variation as a function of input voltage $\mathrm{V}_{\text {batt }}$ is represented by a line whose slope is 0.139 . This slope corresponds to $1 / 7$ for the ratio of the voltage divider.

\subsubsection{PWM Function Test}

Figure 14 and Figure 15 show the PWM signals generated by the PIC16F877A. This is PWM signal amplitude $5 \mathrm{~V}$, a fixed frequency of $1.25 \mathrm{kHz}$ and a variable duty cycle according to the different values of the battery voltage. 


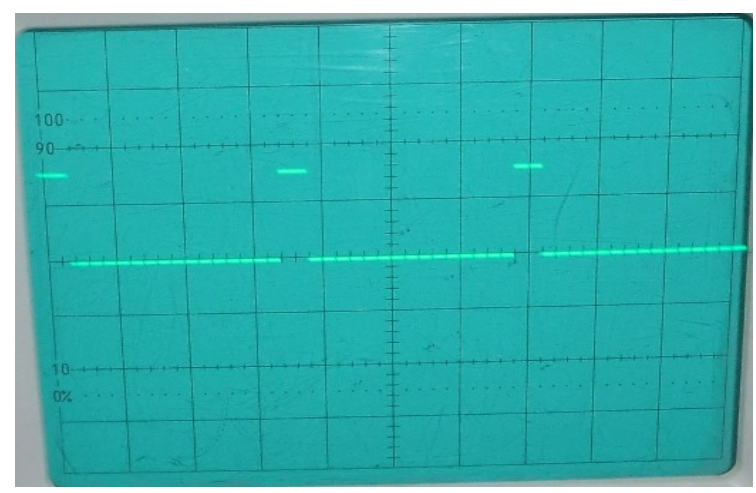

Figure 14. PWM duty cycle $11 \%$ (3V/div, $0.2 \mathrm{~ms} / \mathrm{div})$

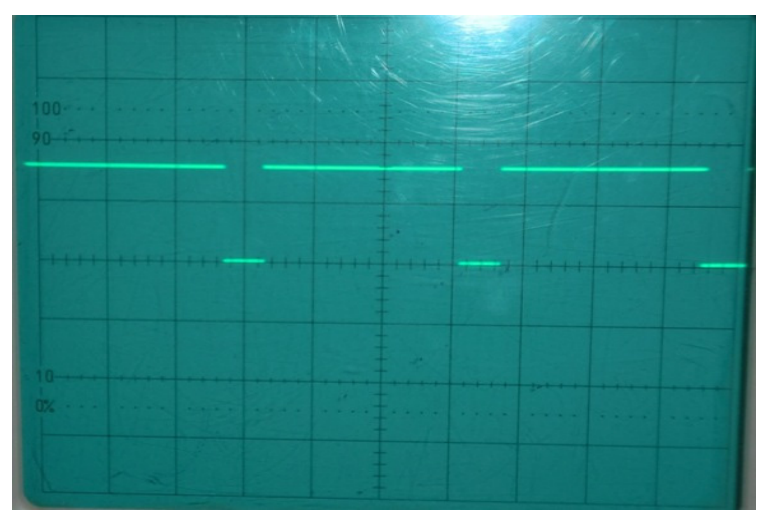

Figure $15 . \mathrm{PWM}$ duty cycle $83 \%(3 \mathrm{~V} / \mathrm{div}, 0.2 \mathrm{~ms} / \mathrm{div})$

\subsubsection{Charge Control Test}

To test the charge control, the variation of the power dissipated as a function of battery voltage is drawn in the Figure 16 on the one hand. On the other hand, the variation of the power dissipated as a function of duty cycle is shown in Figure 17. It is possible to notice that from dissipation threshold set at $28.3 \mathrm{~V}$, a part of the energy produced (excess) is diverted to the overflow resistor. The power dissipated increases according to the battery voltage $\mathrm{V}_{\text {batt }}$ before reaching a maximum of 900 Watts from which it remains constant despite the increase of the battery voltage. During this phase all wind turbine production is dissipated in the overflow resistor because the batteries are full and there is no request by the loads. When the battery voltage reaches again the threshold dissipation, dissipation of power begins to decrease gradually until it becomes zero.

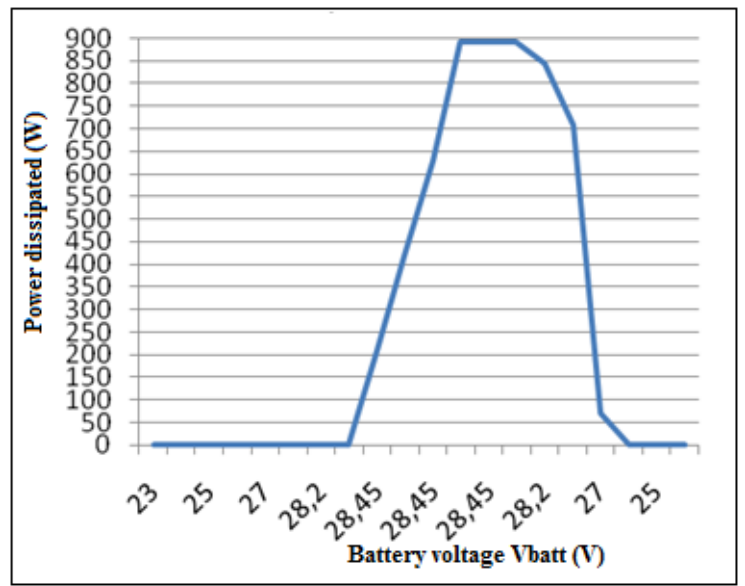

Figure 16. Power dissipated in function of the battery voltage $V_{\text {batt }}$ 
Figure 17 shows the evolution of the dissipated power as a function of duty cycle (D). We note that when the duty cycle is $100 \%$, the total power is dissipated. For a duty cycle of $50 \%$, half of the total production is dissipated.

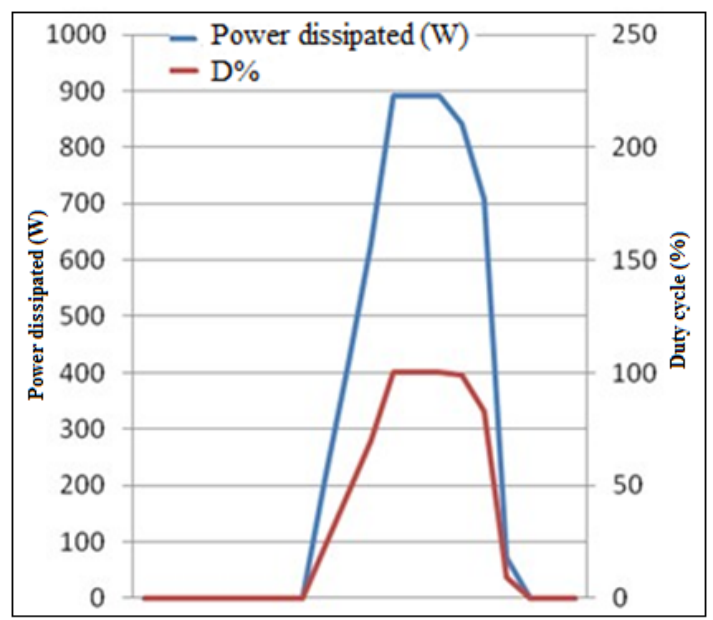

Figure 17. Power dissipated in function of duty cycle

\subsubsection{Control Discharge Function}

If the state of the battery charge is below the low threshold of discharge (VLVD), the controller disconnects the load (use). It is reconnected if the state of battery charge reaches the threshold of reconnection (VAR). Figure 18 shows the change of the control signal of the MOSFET which manages the charge control.

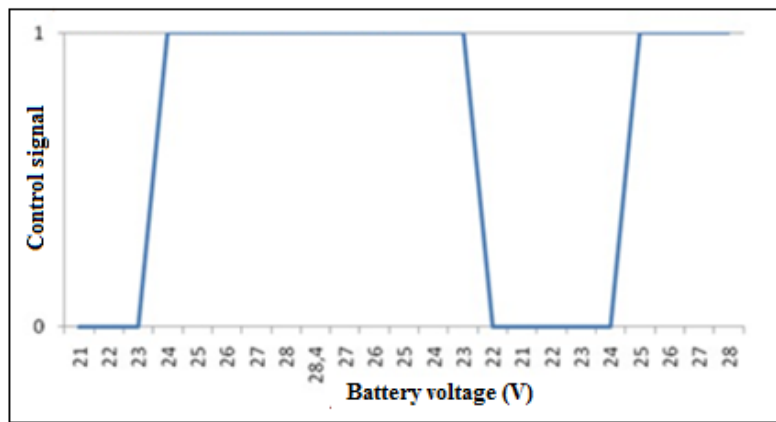

Figure 18. Evolution of the control signal of discharge

\section{Conclusion}

The objective of this work was to develop a controller dedicated to the small wind turbine. The first tests made in conditions of laboratory are rather satisfactory and gave us runways of improvements and optimizations. The oscillograms of the various command signals PWM generated by the PIC microcontroller 16F877 obtained were noted. The main functions were validated: deviation and dissipation of the excess power starting from the fixed thresholds, the disconnection and reconnection of the load according to the state of the battery charge. The correlation between the evolution of the dissipated power and the duty cycle was made obvious fact. In prospect, after the completion of the electronic regulator board which in printed circuit boards, tests will be performed in real conditions.

\section{References}

Amin, N., Azim, M. A., \& Sopian, K. (2008). Development of cost effective charge controller with data acquisition options for PV powered sensor nodes. Photovoltaic Specialists Conference, 2008. PVSC '08, 33rd IEEE.

Datasheet PIC 16F877A. (2012). Microchip Technology Inc. 
Huet, F. (1998). A review of impedance measurements for determination of the state-of charge. Journal of Power Sources, 70.

Kirchev, M. A. (2007). Studies of the pulse charge of lead-acid batteries for PV applications, part II. Impedance of the positive plate revisited.

Koutroulis, E., \& Kalaitzakis, K. (2004). Novel Battery Charging Regulation System for Photovoltaic Applications. IEEE Proc. Electr. Power Appl., 151(2), 191 - 197.

Mayeux, P. (2002). Apprendre la Programmation des PIC par l'Expérimentation et la Simulation. ETSF 2ème édition 2002.

Ndiaye, A., Dzahini D., Ndiaye, P. A., Kébé, C. M. F., \& Sambou, V. (2012). Impact of injected charges, clock noise and Operational Amplifier imperfections on the Sample and Hold (SH) overall performance. Applied Physics Research, 4(4), 18-25. http://dx.doi.org/10.5539/apr.v4n4p18

Ndiaye, A., Judalet, V., Kébé, C. M. F., \& Ndiaye, P. A. (2010). Développement d'un régulateur de charge/décharge de batterie à seuils configurables pour des applications éoliennes. Journal des Sciences Pour l'Ingénieur, 1(12), 57-62. http://www.ajol.info/index.php/jspi/article/view/67976

Usher, E. P., \& Ross, M. M. D. (1998). Recommended Practices for Charge Controllers. Report IEA PVPS T3-05.

\section{Copyrights}

Copyright for this article is retained by the author(s), with first publication rights granted to the journal.

This is an open-access article distributed under the terms and conditions of the Creative Commons Attribution license (http://creativecommons.org/licenses/by/3.0/). 